\title{
PERONEUS QUARTUS MUSCLE: ITS INCIDENCE AND CLINICAL IMPORTANCE
}

\section{Amal Yousif Ahmed Elhag Mustafa*, Wardah Abdullah Mohammed, Alasmari, Abdullah Glil Alkushi, Ashraf Mohamed Elsayed Ali Sakran.}

Department of Human Anatomy, Faculty of Medicine, Umm al Qura University, Makka, Saudi Arabia.

\section{ABSTRACT}

Introduction and objectives: Muscular variations in the lower limb are very common. They have been described by many authors when performing cadaveric dissections and when using the different imaging techniques.

Materials and Methods: Twenty lower limbs of adult cadavers, were dissected. Lower limbs deformed by trauma, malformations and scars were excluded. The compartment was examined for the presence of an accessory muscle. If this is present, the dissection was extended and the site of its origin and insertion and passage in the retromalleolar groove was noted.

Result: A peroneus quartus was present in 4(20\%) of the 20 legs. Two different area of origins and insertions. Two of them arose from the peroneus brevis muscle, and the other two from the distal fibula .three of the muscles were inserted into the retrotrochlear eminence of the calcaneum, the remaining one was inserted into the base of the first metatarsal bone.

Conclusions: This study will supplement our knowledge on the possible variations of the muscles in this region, which would be useful for lower limbs surgeons.

KEY WORDS: Peroneus Quartus, Anomalous, Variations.Introduction.

Address for Correspondence: Dr. Amal Yousif Ahmed Elhag Mustafa, Department of Human Anatomy, Faculty of Medicine, Umm al Qura University, Makkaha, Saudi Arabia.

E-Mail: amaalahmed50@yahoo.com

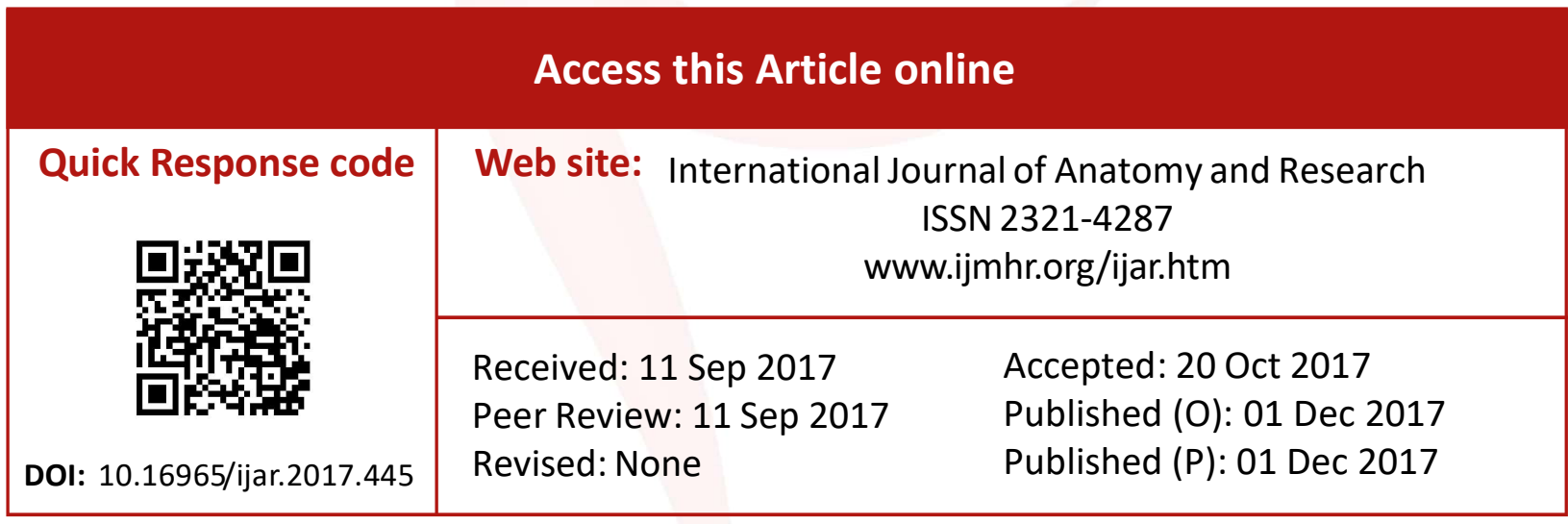

\section{INTRODUCTION}

Muscular variations in the lower limb are very common. They have been described by many authors when performing cadaveric dissections and when using the different imaging techniques.

The presence of these muscles is frequently asymptomatic, but sometimes it can cause symptoms due to overcrowding and mechanical compression of adjacent structures.

The lateral compartment of the leg contains the peroneus longus and peroneus brevis muscles.
The peroneus quartus muscle is one of the accessory muscles present in the lateral compartment of the leg. It is said to have been first described by Ottoin 1816 and was studied in depth in 1923 by Hecker [1] who estimated its incidence to be $13 \%$ in the general population. There are only a few studies concerning this muscle. surgeons should be aware of the possible presence of the peroneus quartus muscle, not only because of possible associated pathology, but also for use in surgical reconstruction. Various anatomists have described it and 
given it different names according to its various origins and insertions. Sobel, W Levy and Bohne [2] described the anatomical variations of the muscle in a cadaver study on 124 legs with particular reference to the origins and insertions of the different anomalous muscles in the lateral compartment and suggested that these should all be referred to as variants of the same muscle, the peroneus quartus. They showed that it was present in $21.7 \%$ of cadavers.

The peroneus quartus muscle, arises from the lower third of the fibula, peroneus brevis muscle, and/or peroneus longus muscle. However, its distal insertion has shown great variability, most often inserting onto the lateral surface of the calcaneus on the retrotrochlear eminence [3]. Believed to be an evolutionary acquisition for bipedal gait, the peroneus quartus muscle is unique to humans, assisting with eversion of the lateral border of the foot, pronation of the foot against the walking surface, and lateral stabilization of the ankle [1-6]. The peroneus quartus muscle was first described by Otto in 1816 [3] and has since been termed the peroneus sextus, peroneus calcaneus externus, peroneocuboidian, peroneus accessorius, peroneus medius [7], and peroneus muscle of the tarsus [1]. Anatomists, surgeons, and radiologists have discovered slight variations in the distal insertion of the peroneus quartus, resulting in both increased and ambiguous nomenclature [8-11].

The reported points of insertion include (from proximally to distally): retrotrochlear eminence of the calcaneus, the fibular (peroneal) trochlea of the calcaneus, tendons of the fibularis longus and brevis muscles, the cuboid, and the fifth metatarsal [10,12-14]. In 1923, Hecker [1] classified the peroneus quartus variants into 3 categories according to the insertion onto the calcaneus (peroneocalcaneus externum), cuboid (peroneocuboideus), or tendon of peroneus longus (peroneoperoneolongus). However, the peroneoperoneolongus muscle is now referred to as the peroneus accessorius $[10,15,16]$. Other peroneus quartus variants include the peroneus digiti minimi, which inserts onto the fifth metatarsal [10] and the peroneotalocalcaneus muscle [17]. With so many variations of the peroneus quartus muscle, 2 studies attempted to resolve the nomenclature issues by suggesting that the peroneus quartus muscle inserts onto the lateral aspect of the calcaneus and the variants of the muscle have other distal attachments $[10,14,12,18]$.

This study aims at investigating the incidence, anatomical variations and possible pathology relating to the peroneus quartus muscle.

\section{MATERIALS AND METHODS}

This study was conducted at the Faculty of Medicine, Umm AL_qura University, Makka, Saudi Arabia between March 2016 and September 2017. Twenty lower limbs of adult cadavers, were dissected to perform this study. Their ages range between 45 and 77 years old. Lower limbs deformed by trauma, malformations and scars will be excluded. Each limb was dissected by an incision which was start about $10 \mathrm{~cm}$ proximal to the lateral malleolus and end $5 \mathrm{~cm}$ distal to it. The compartment was examined for the presence of an accessory muscle. If this is present, the dissection was extended and the site of its origin and insertion and passage in the retromalleolar groove was noted. All anatomical variations was registered, recorded and photographed.

\section{RESULTS}

A peroneus quartus was present in $4(20 \%)$ of the 20 legs which were dissected (Figure 1). The muscles which were identified two different area of origins and insertions. Two of them arose from the peroneus brevis muscle, and the other two from the distal fibula .three of the muscles were inserted into the retrotrochlear eminence of the calcaneum(figure 1), the remaining one was inserted into the base of the first metatarsal bone.

The peroneus quartus muscle shown in Figure 3 arose from peroneus brevis. It passed as a separate tendon posterior to peroneus brevis and inserted into the eminence of the calcaneum.

Figure 2 show it arising from the distal part of the fibula. The muscle belly was short and its tendon lay between peroneus longus and brevis in the retromalleolar groove and also inserted into the eminence of the calcaneum.

One cadaver had peroneus quartus muscles with origin from peroneus brevis and the insertion into the base of the fifth metatarsal bone. 
Fig. 1: Showing the peroneus quartus muscle (3) at its insertion in the retrotrochlear eminence, peroneus longus (1), and peroneus brevis (2).

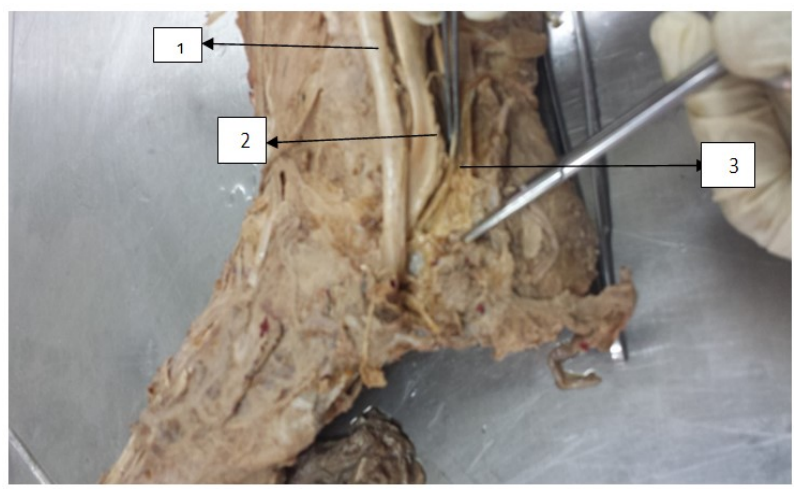

Fig. 2: showing the peroneus quartus muscle (3) arising from the distal fibula. (1, peroneus longus; 2 , peroneus brevis).

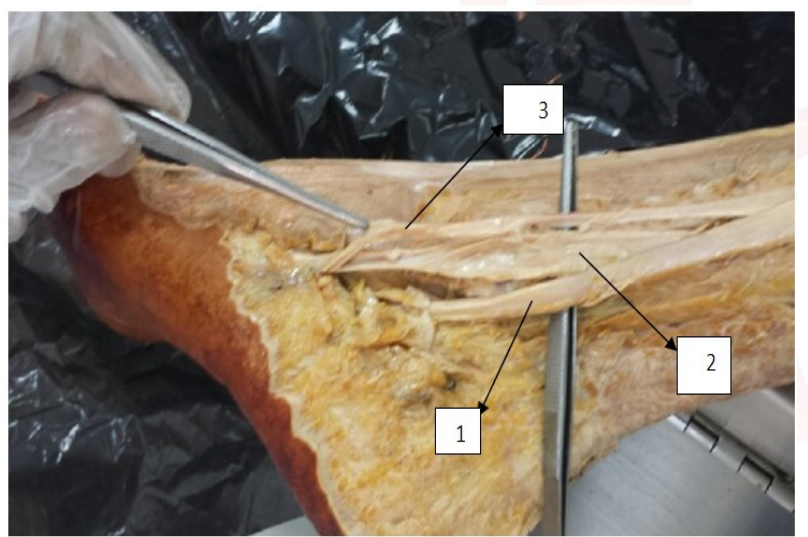

Fig. 3: showing the origin of peroneus quartus muscle (3) from the peroneus brevis muscle (2).

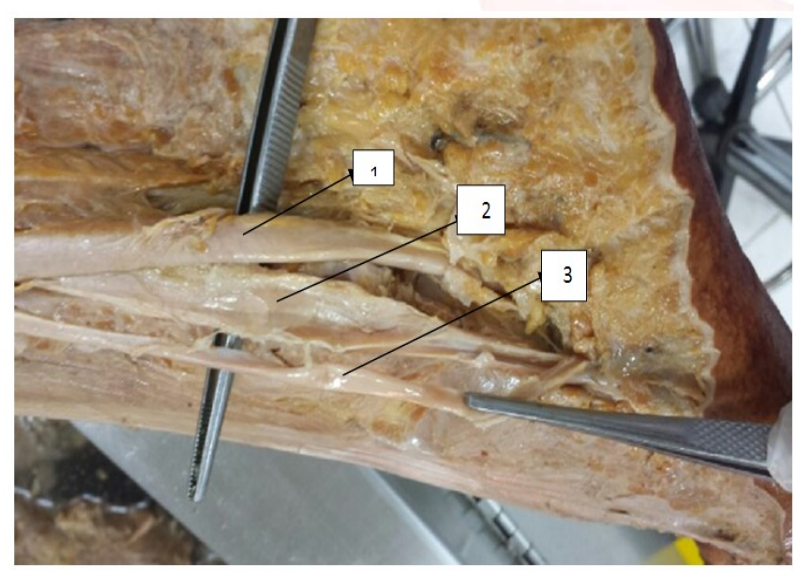

Fig. 4: showing the peroneal compartment muscles. Peroneus longus (1), peroeus brevis (2) and peroneus quartus.

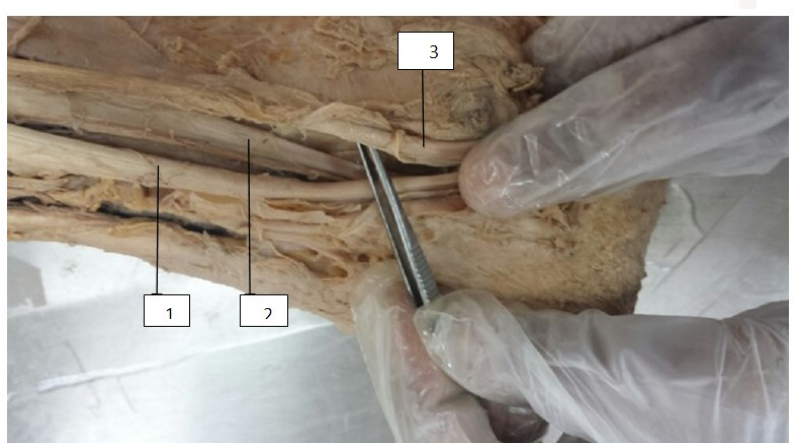

Int J Anat Res 2017, 5(4.3):4691-94. ISSN 2321-4287

\section{DISCUSSION}

Knowledge of the anatomy of the peroneal muscles and its variations is important to surgeons dealing with pathologies in this region.

There are no precise data on the incidence of the peroneus quadrus muscle in the literature, and the studies are mainly based on the findings of many years ago [19].

In this study we found the incidence of peroneus qurtus was $20 \%$ in our specimens. Bhargava et al [20] gave the incidence of peroneus quadrus as $15.5 \%$. Reimen [21] reported the presence of peroneus quadrus as $79.5 \%$. Based on these data, Yammine [22] stated that there were differences regarding incidence of the muscle and declared that ethnicity was important in considering the incidence of peroneus quadrus in each community.

In our specimen we noticed two different area of origins and insertions. Two of them arose from the peroneus brevis muscle, and the other two from the distal fibula three of the muscles were inserted into the retrotrochlear eminence of the calcaneum, the remaining one was inserted into the base of the first metatarsal bone.

As in previous reports, The most frequent origin was from the muscle fibres of peroneus brevis and its most frequent insertion was into the retrotrochlear eminence of the calcaneum $(12,23)$.

\section{CONCLUSION}

Surgeons should be aware of the existence of this muscle, not only because of possible associated pathology, but also because of its potential use in reconstructive surgery. peroneal muscles which would be important for reconstructive foot surgeons attempting to repair this area. This study will supplement our knowledge on the possible variations of the muscles in this region, which would be useful for lower limbs surgeons.

\section{Conflicts of Interests: None}

\section{REFERENCES}

[1]. Hecker P. Study of the peroneus of the tarsus. Anat Rec 1923;26:79-82.

[2]. Sobel M, Levy ME, Bohne WH. Congenital variations of the peroneus quartus muscle: an anatomic study. Foot Ankle 1990;11:81 
[3]. Sarrafian SK. In: Sarrafian's Anatomy of the Foot and Ankle: Descriptive, Topographic, Functional, ed 3, pp. 240-245, edited by AS Kelikian, Lippincott, Williams \& Wilkins, Philadelphia, 2011.

[4]. Trono M, Tueche S, Quintart C, Libotte M, Baillon JM. Peroneus quartus muscle: a case report and review of the literature. Foot Ankle Int. 1999;20:659-662.

[5]. Wachter S, Beekman S. Peroneus quartus: a case report. J Am Podiatr Med Assoc 1983;73:523-524.

[6]. Athavale SA, Gupta V, Kotgirwar S, Singh V. The peroneus quartus muscle: clinical correlation with evolutionary importance. Anat Sci Int. 2012;87:106110.

[7]. Bejjani FJ, Jahss MH. Le Double's study of muscle variations of the human body part I: muscle variations of the leg. Foot Ankle 1985;6:111-134.

[8]. Wood J. Variations in human myology observed during the winter session of 1867- 1868 at King's College, London. Proc R Soc London 1868;16:483525.

[9]. Macalister A. On muscular anomalies in human anatomy, and their bearing upon homotypical myology. Proc R Irish Acad. 1866-1869;10:121-164.

[10]. Sobel M, Levy ME, Bohne WH. Congenital variations of the peroneus quartus muscle: an anatomic study. Foot Ankle 1990;11:81-89.

[11]. Saupe N, Mengiardi B, Pfirrmann CW, Vienne P, Seifert $B$, Zanetti M. Anatomic variants associated with peroneal tendon disorders: MR imaging findings in volunteers with asymptomatic ankles. Radiology 2007;242:509-517.

[12]. Cheung YY, Rosenberg ZS, Ramsinghani R, Beltran J, Jahss $\mathrm{MH}$. Peroneus quartus muscle: MR imaging features. Radiology 1997;202:745-750.

[13]. Gumusalan Y, Ozbag D. A variation of fibularis quartus muscle: musculus fibulocalcaneus externum. Clin Anat 2007;20:998-999.

[14]. Zammit J, Singh D. The peroneus quartus muscle: anatomy and clinical relevance. J Bone Joint Surg 2003;85:1134-1137.

[15]. White AA III, Johnson D, Griswold DM. Chronic ankle pain associated with the peroneus accessorius. Clin Orthop Relat Res 1974;103:53-55.
[16]. Regan TP, Hughston JC. Chronic ankle "sprain" secondary to anomalous peroneal tendon: a case report. Clin Orthop Relat Res 1977;123:52-54.

[17]. Tubbs RS, May WR, Shoja MM, Loukas M, Salter EG, Oakes WJ. Peroneotalocalcaneus muscle. Anat Sci Int 2008;83:280-282.

[18]. Wang XT, Rosenberg ZS, Mechlin MB, Schweitzer $M E$. Normal variants and diseases of the peroneal tendons and superior peroneal retinaculum: MR imaging features. RadioGraphics 2005;25:587-602.

[19]. Sönmez M, Koar I, Çimen M. The supernumerary peroneal muscles: case report and review of the literature. Foot and Ankle Surgery 2000;6:125-129.

[20]. Bhargava KN, Sanyal PK, Bhargava SN. Lateral musculature of the leg as seen in a hundred Indian cadavers. Indian J Med Sci 1961;15:181-185.

[21]. Reimann R. Der variable streckapparat der kleinenzehe. Gegenbaurs Morphol Jahrb 1981;127:188-209.

[22].Yammine K. The accessory peroneal (fibular) muscles: peroneus quartus and peroneus digiti quinti. A systematic review and meta-analysis. Surg Radiol Anat 2015;37:617-627.

[23]. Le Double A. A study of the muscle variations of the human body: part 1 . Muscle variation of the leg. (English translation). Foot Ankle 1985;6:111-34.

How to cite this article:

Amal Yousif Ahmed Elhag Mustafa, Wardah Abdullah Mohammed, Alasmari, Abdullah Glil Alkushi, Ashraf Mohamed Elsayed Ali Sakran. PERONEUS QUARTUS MUSCLE: ITS INCIDENCE AND CLINICAL IMPORTANCE. Int J Anat Res 2017;5(4.3):4691-4694. DOI: 10.16965/ijar.2017.445 